\title{
Engineer's approach to conservation
}

\author{
Stephen Fernandez MEng, CEng, MIStructE, MICE, Conservation \\ Accredited Engineer \\ Associate Director, Arup, Nottingham, UK (stephen.fernandez@arup.com)
}

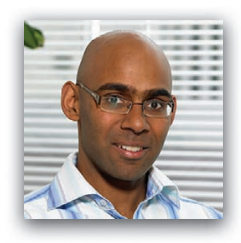

This paper discusses some of the considerations that engineers may need to take when assessing and working on historic buildings or assets. It outlines the philosophy of conservation and draws on experience gained using case studies of projects that the author has worked on for illustration. It highlights not only that an engineer needs to develop a wide array of skills and knowledge in order to carry out any works on historic structures, but also that an engineer can have a pivotal role in helping to protect and prolong the life of cultural heritage.

\section{Introduction}

A significant proportion of the built environment is historic, which in itself creates a climate and context (Prizeman, 2015). Conservation is important as it secures the protection of built heritage and will help to prolong the life of cultural heritage for society. The basis of any conservation works can be due to social, cultural, economic or environmental reasons, although it is often a combination of these. It can include adapting, restoring, protecting and rehabilitating monuments, buildings, groups of buildings and sites.

Over the years a number of important documents have helped to establish a philosophy towards conservation. In 1877, the Society for the Protection of Ancient Buildings set out a manifesto which was the starting point for the policy statements and international charters that were established in the twentieth century. The Athens, Venice and Burra Charters are the most well-known international charters today (Icomos, 1931, 1964).

The Athens Charter was established in 1931 at a conference organised by the International Museum Office in Athens, which outlined basic principles for an international code of practice for conservation. Following this, the Venice Charter was established in 1964 as the International Charter for the Conservation and Restoration of Monuments and Sites. This defined the basic tenets of what is now accepted to be an appropriate approach towards conservation. It marked an important milestone and was adopted by the newly formed International Council on Monuments and Sites (Icomos).

In 1981, the Australia Icomos Charter for the Conservation of Places of Cultural Significance was published, and is now referred to as the Burra Charter. This developed the principles outlined in the Venice Charter, but in a format which would be practical and useful in Australia.

This is an important document, as it was the first charter to identify the importance of 'cultural significance'. It explicitly set out a clear process for conservation based on significance, with a series of steps that can be followed. These steps include safeguarding the asset, understanding the place and its significance and developing policies for managing that significance. The Burra
Charter includes a comprehensive list of definitions relating to conservation and describes the following conservation processes

- retention or reintroduction of a use

- retention of associations and meanings

- maintenance, preservation, restoration, reconstruction, adaptation and interpretation

- will commonly involve a combination of more than one of these.

Following these, numerous other standards and formal recommendations have been published which have helped to define the approach towards conservation. For example, BS 7913:2013, 'Guide to the principles of conservation of historic buildings' (BSI, 2013), for use in the UK, describes best practice in the management and treatment of historic buildings and provides guidance through various stages from initially looking at a building to completion.

Conservation projects vary considerably, but generally consist of either preservation, restoration, renovation or refurbishment, or a combination of these (Hallum, 2006). Preservation helps to maintain the condition of the building or asset and can involve doing nothing or very little. Restoration involves works to return a building or an asset (or parts of it) to its original state or former condition and appearance. Although the word has become associated with major interventions of rebuilding works, even small interventions, such as replacing a missing detail or component, can also be classified as restoration. However, it is necessary that any interventions must be based on verified evidence. Renovation works are repairs or improvements to a building or asset and can include reconstruction, often undertaken to replace buildings or parts of buildings following fire, war damage, earthquake or other disasters.

The charters have also led Historic England (previously English Heritage) to publish the document Conservation Principles, Policies and Guidance for the Sustainable Management of the Historic Environment (English Heritage, 2008). This provides a logical approach to making decisions and offers guidance for conservation works. 
Historic England describes conservation works as the sustainable management of the historic environment. It provides useful definitions for common terms associated with heritage protection and describes conservation as the process of maintaining and managing change to a heritage asset in a way that sustains and where appropriate enhances its significance' (English Heritage, 2008). Historic England also defines conservation as 'the process of managing change to a significant place in its setting in ways that will best sustain its heritage values, while recognising opportunities to reveal or reinforce those values for present and future generations' (Department for Communities and Local Government, 2012). This suggests that changes may be required and acknowledges that many buildings and sites may have undergone a process of change from the time of original development.

The preferred approach towards conservation is that of minimum intervention (i.e. to preserve as found and do nothing), and it is still important to ask the following fundamental questions from the outset.

- Can it be preserved as found?

- Can interventions be minimised?

- Are like-for-like repairs adopted?

- Are repairs or changes sympathetic?

- Are any repairs reversible?

These are important questions that should be asked at the start of any conservation project and are equally relevant after completion of any works to assess the approach taken. While it may not be possible to answer these questions fully at the start, they are important considerations and can give some direction towards the most appropriate approach (Hume, 1997).

Conservation is very complex and not only requires a technical approach from an engineer, but may also need to address a variety of wider aspects, such as cultural and artistic qualities, or be based on a combination of scientific and humanistic values. Therefore, conservation is not just related to a single discipline. With any conservation work, it is essential to have an understanding of the way each independent discipline works and appreciate the symbiotic process.

\section{Preserve as found}

The starting point should always be to 'preserve as found', in order to retain as much of the building or asset as possible. Minimum intervention is based on the fundamental question of whether any work needs to even be carried out at all. This can be difficult as it is highly likely that the original design may fall short of requirements set out in current design standards, codes of practice or building regulations. For example, it is common to find an old building with walls out of plumb, cracks in walls, sagging floor joists or splaying roof trusses. However, if the building has survived for hundreds of years, it may not be necessary to carry out a repair, remove these elements or the use the most extreme measure to rebuild. These aspects can be important 'characteristics', and while some localised strengthening works may be necessary, the distortions can be an important 'layer' in the building's history which help tell its story and are part of the richness of a historic building.

The approach to preserve as found can be challenging, particularly if defects are encountered. Rather than concluding that the building or elements do not comply with current design standards or codes of practice, it is more important to try to understand how the building 'works', and this can be conducted through a detailed appraisal and assessment. This approach may prove that, despite the initial appearance of structural inadequacy, minimal works are necessary to prolong its life. This is the essence of the 'philosophy of conservation'. In order to preserve, engineers need not only have the confidence to rely not just on current design standards or codes of practice, but also have a sympathetic approach with knowledge of the craft of construction using traditional techniques and understand the history of the materials used and the structural form.

An approach often taken for old buildings is the ' 100 -year rule', where, assuming that a building does not show any signs of distress, its historical performance can justify its future performance. This relies on it being at least 100 years old with no signs of structural distress, an identifiable stability system and no change in loading. However, the 100-year rule should be used with appropriate caution as there is often a natural process of material change throughout a building's life, which may not be immediately obvious. This approach must also be carefully considered on an individual case-by-case basis. For example, there is an argument that failure of brittle materials, such as cast iron, may always be a risk and therefore these materials also require an ongoing maintenance plan.

Developing a better understanding of a building or asset's history will help to improve confidence in the structure and its load paths and whether it is capable of surviving for a specific purpose without intervention. If an observed defect has been present for a considerable amount of time with no recent noted distortion, it may not actually be necessary to carry out any modifications or repair works. If this approach is taken, it is worth asking, what reasonable changes will the building experience in the foreseeable future? This may dictate the level of intervention required and whether this approach will unreasonably restrict the occupier.

The basis for establishing if a building or monument can be preserved as found or for determining the level of intervention is not an exact science, but requires sound judgement and can be considered as the 'art of structural engineering'.

\subsection{Illustrating the preserve-as-found approach at the Arkwright Building, Nottingham}

The Grade II*-listed Arkwright Building at Nottingham Trent University, built in 1877 (see Figure 1), had suffered significant 
Engineer's approach to conservation Fernandez

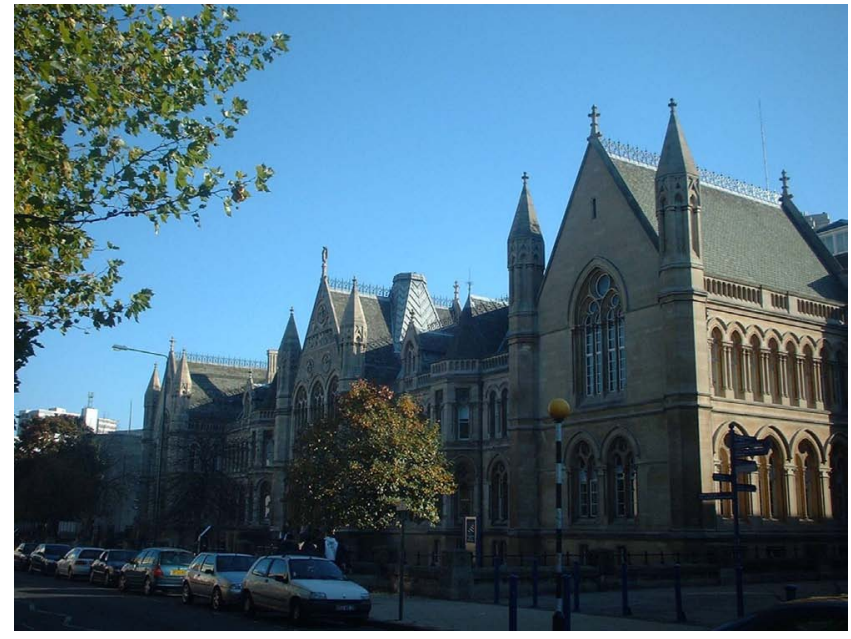

Figure 1. The Arkwright Building, Nottingham

historical movement due to settlement, with surveys and inspections identifying numerous cracks and leaning walls (see Figure 2). However, rather than instantly condemning the existing structure or attempting repair works (which would have been excessively expensive due to the extent), detailed investigations were conducted to help understand why the building had moved, where the movement had occurred and whether it was continuing to move. The majority of the walls were constructed with a combination of brickwork and stone, and there were signs of previous settlement (historical data indicated that tie rods were installed in the 1880 s in response to settlement that occurred soon after construction - see Figure 3). Due to these issues, numerous crack monitors were set up at the locations of the larger cracks to monitor any movement prior to the start of the works, during the works on-site and also for a period after the works had been

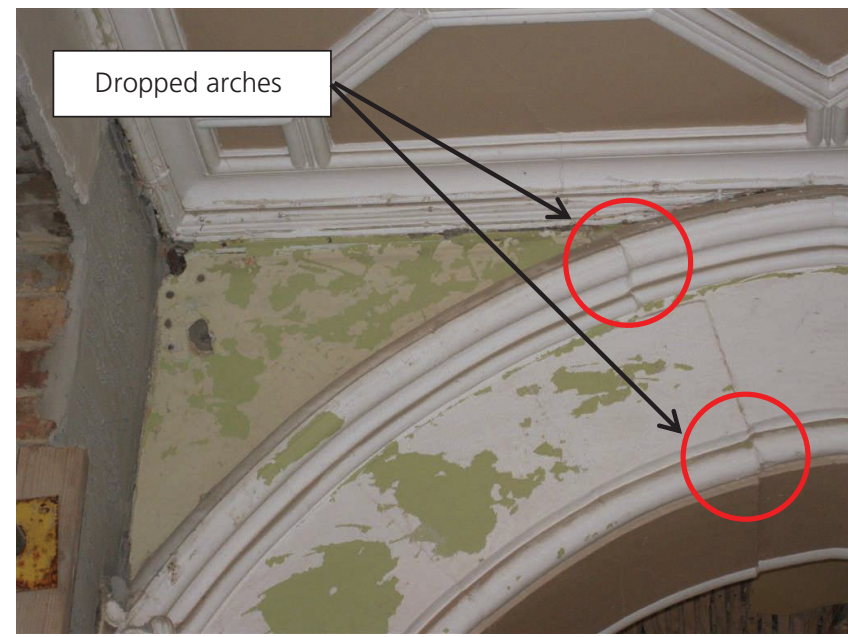

Figure 2. Evidence of settlement around the Arkwright Building with dropped arches completed. This was undertaken to identify also any fluctuating movement due to seasonal changes, and the data were plotted on a timeline to help understand how the building might have been moving.

The building clearly experienced movements and settlements historically, and further movement would be expected if the building were to be subjected to significant alterations to loads on its foundations. Therefore, the design approach was to minimise changes in the loading and, where change was unavoidable, to enhance and strengthen the structure only locally. Although the building will continue to move, it was not considered to be cost effective (or probably $100 \%$ successful) to try to stop the building moving altogether and would have involved attempting to underpin the majority of the walls, which would have been very expensive, time consuming and disruptive.

\subsection{Illustrating the preserve-as-found approach at St Pancras Renaissance Hotel, London}

Works at St Pancras Renaissance Hotel involved restoring the nineteenth-century Grade I-listed building to bring the building back into use after 20 years of dereliction. The brief was to convert the existing building into a new five-star hotel with luxury apartments of similarly high quality (see Figure 4). Although it was being converted back to its original use as a luxury hotel, some major works were necessary to meet the requirements for a modern 'luxury' building, particularly for servicing (e.g. the original building did not have sufficient provision for plumbing, which would be essential, particularly for the grander suites). Therefore, the works required a balance between preservation and modification, but the general approach was to minimise alterations. The existing load paths were maintained and remained unaltered as much as possible, and it was important to ensure that a global load balance existed.

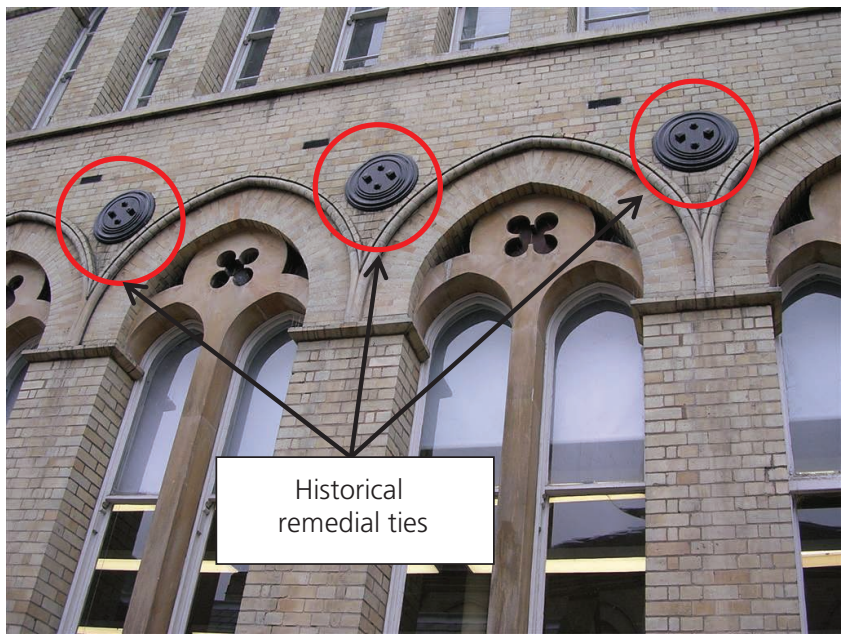

Figure 3. Remedial ties were installed soon after the Arkwright Building had been opened 


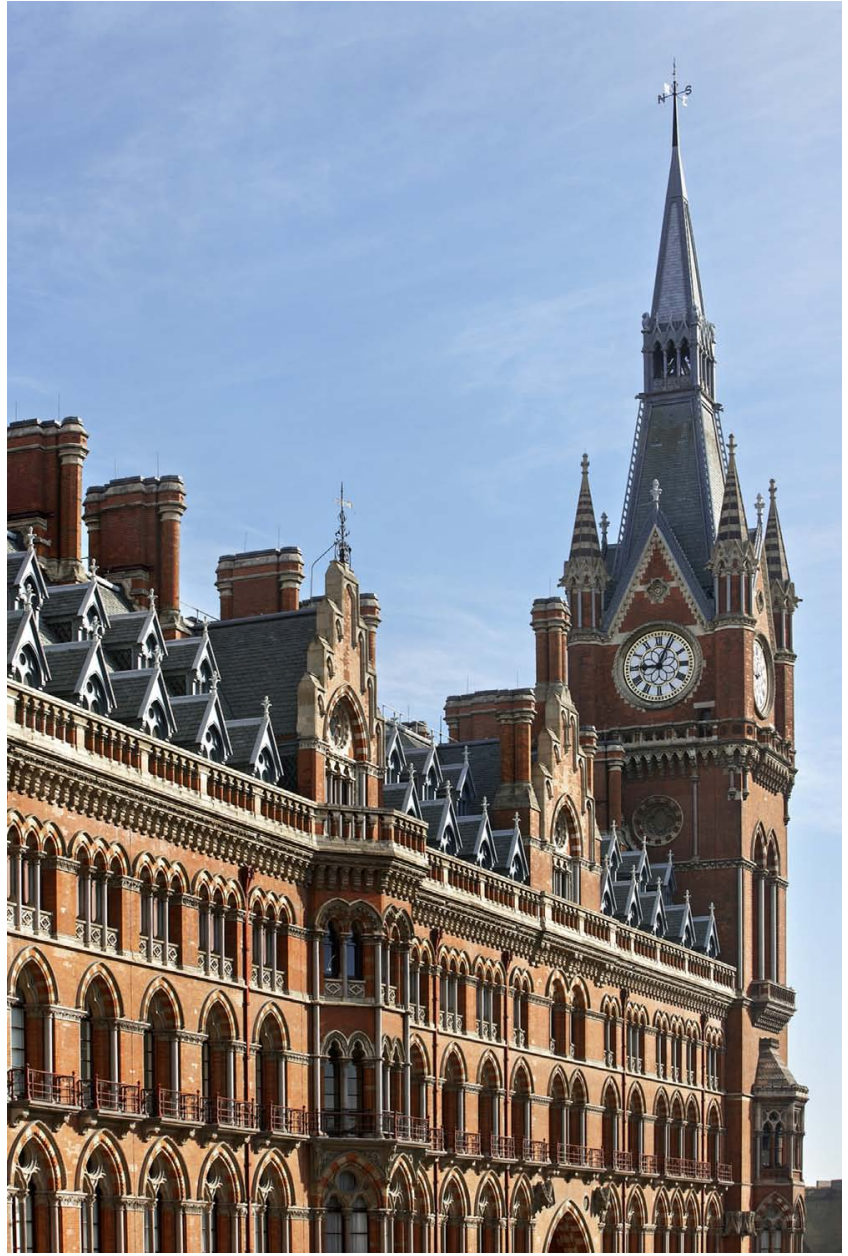

Figure 4. The St Pancras Renaissance Hotel, London (@ Hufton + (row)

The structure consists of heavy masonry load-bearing walls, which were generally found to be in good condition without obvious signs of distress. Some localised repairs have been carried out where essential, but the majority of walls with more minor defects have been left in their existing state and require ongoing monitoring.

The floor construction was found to vary across the building with three different types, with the majority of areas formed by a proprietary system known as the 'Moreland floor' (developed by Richard Moreland). This floor system consists of curved bow trusses forming an arch supporting coarse lime concrete laid on corrugated iron sheeting, with timber floor boards on bearers over the coarse lime concrete (see Figure 5). Structural assessments were undertaken to determine the capacity of this system, which included testing cored concrete samples and wrought iron tokens from the floor and masonry samples from the walls. This information initially suggested that the floor system was capable of supporting only its own self-weight. Further detailed analysis was therefore carried out, which indicated that the floor system works in a much more complex way, with a combination of spanning, arching and

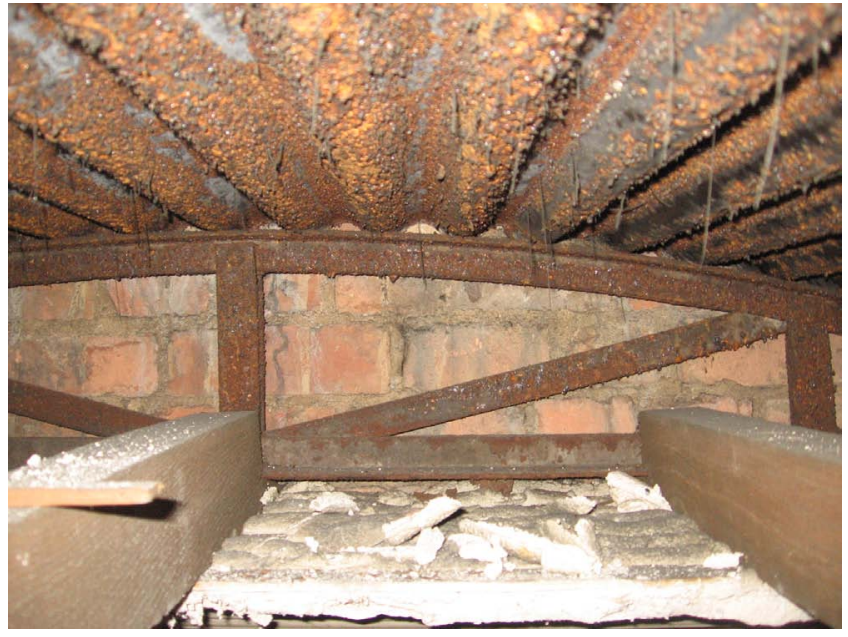

Figure 5. The existing proprietary Moreland floor system used at St Pancras Renaissance Hotel

cross-vaulting. This helped to conclude that the floors were generally capable of supporting the loading for residential, hotel and corridor uses, with only localised repairs necessary.

While some modification work was necessary, some of the grandest locations and features of the building have been preserved as found with minimal works, such as the grand staircase, which has been restored with only minor cosmetic works required (see Figure 6).

\section{Carry out minimum intervention}

The preserve-as-found approach is not always practical, and interventions and alteration works may be unavoidable to prolong the life of a building or an asset. Any intervention needs to be considered carefully, as it is very easy to conclude simply that repair works are required or, worse still, that the building or asset has reached the end of its useful life and should be demolished. Prior to designing any intervention, it is important to first understand the building's construction and the cause of the decay. This examination and appraisal will help to build a better understanding of the existing fabric, the cause of the defects that have occurred and whether any intervention works are really necessary.

One example is the intervention necessary when considering repairs to masonry walls. The actual construction of walls and the period when they were built can influence their behaviour, and the performance of different types of walls can vary significantly. Modern buildings generally rely on an impervious outer layer or system of barriers to prevent the penetration of moisture, but the majority of masonry walls constructed before the nineteenth century generally allow any moisture absorbed by the fabric to evaporate from the surface. Acceptable internal dry conditions may have been achieved due to the thickness of the wall (Hughes, 1986), although it is worth noting that as buildings were more draughty, more natural ventilation occurred. These walls were 
Engineer's approach to conservation Fernandez

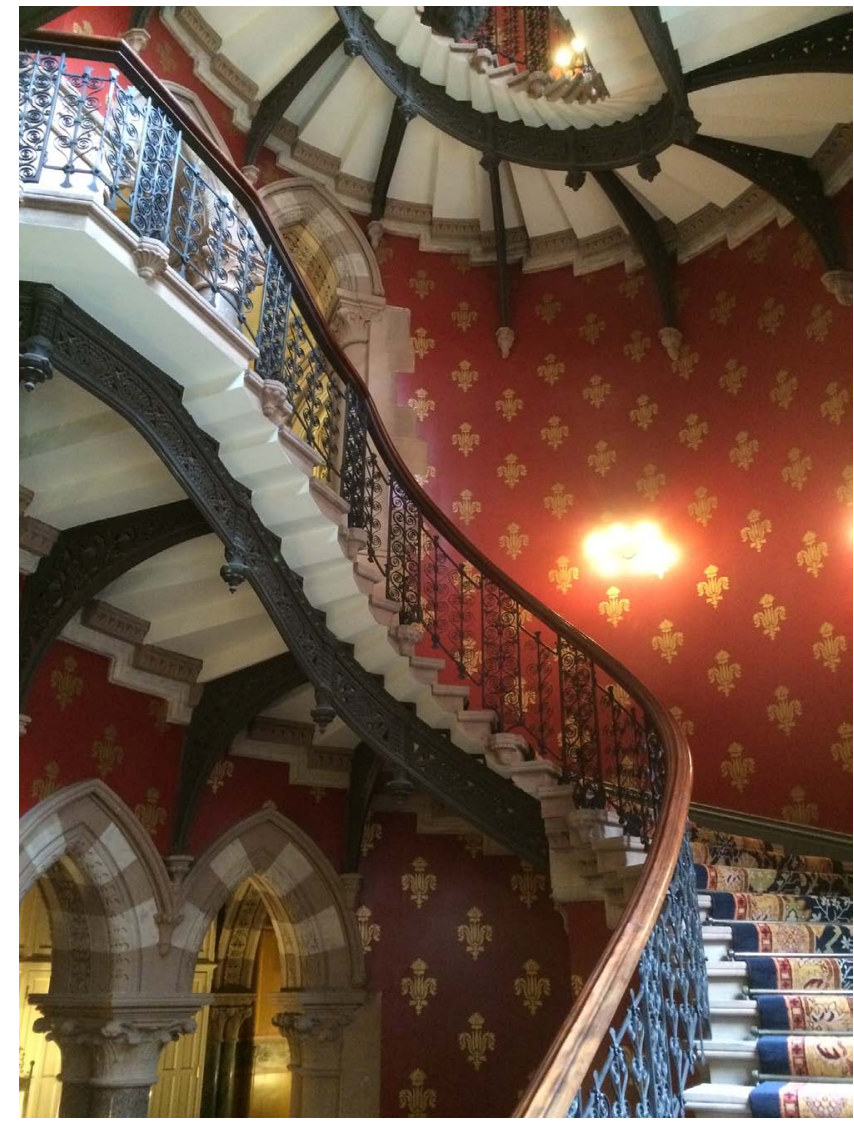

Figure 6. The grand staircase at St Pancras Renaissance Hotel has been restored with only minimal works carried out

usually constructed using lime mortars, which are often more permeable than the brick or stone that they bond. The concept behind the construction of old buildings is that any moisture entering the wall can also evaporate, particularly from the joints.

There have been many cases where modern repair works have been carried out on historic masonry walls by using cement-based pointing or renders. While at the time this would have been considered to be a repair to enhance the life, this form of intervention has been found to be actually detrimental. Cementbased mortars are hard and brittle materials, relatively non-porous, and may not respond in the same way to atmospheric changes as the surrounding masonry. This form of pointing can change the way that the masonry wall behaves and often results in the masonry decaying due to its porous nature, compared with the impervious nature of cement-based mortar.

Conservation is based on respect for the existing fabric and requires a cautious approach to minimise the extent of any changes wherever possible. Interventions may be necessary, particularly if required to prolong the life, but should not detract from the interesting parts of the building, the balance of its composition or its relationship with its surroundings.

\subsection{Illustrating minimum intervention at the} Symington Building, Market Harborough

It was possible to avoid carrying out significant repair works on the Victorian Grade II-listed Symington Building in Market Harborough (see Figure 7) by developing a better understanding of the defects encountered. This building consists of load-bearing perimeter solid masonry with internal wrought iron circular columns supporting wrought iron beams and timber floor joists. The perimeter masonry was found to have suffered from decay, with blown brickwork faces and perished mortar joints. It was important to understand why this had happened prior to designing any form of repair, and the approach adopted was to carry out repairs only where absolutely necessary.

Previous cement-based mortar repairs had caused spalling of the brickwork faces as cement-based mortar is a more impermeable material and had resulted in moisture being trapped (see Figure 8). The structural integrity of the individual bricks was assessed, and previously attempted cement mortar repairs were simply removed. These mortar joints (and other significantly perished mortar joints) were repointed using traditional limebased mortar, not only providing future protection from water ingress but also allowing the brickwork to 'breathe'. The majority of the brickwork was considered to be acceptable structurally;

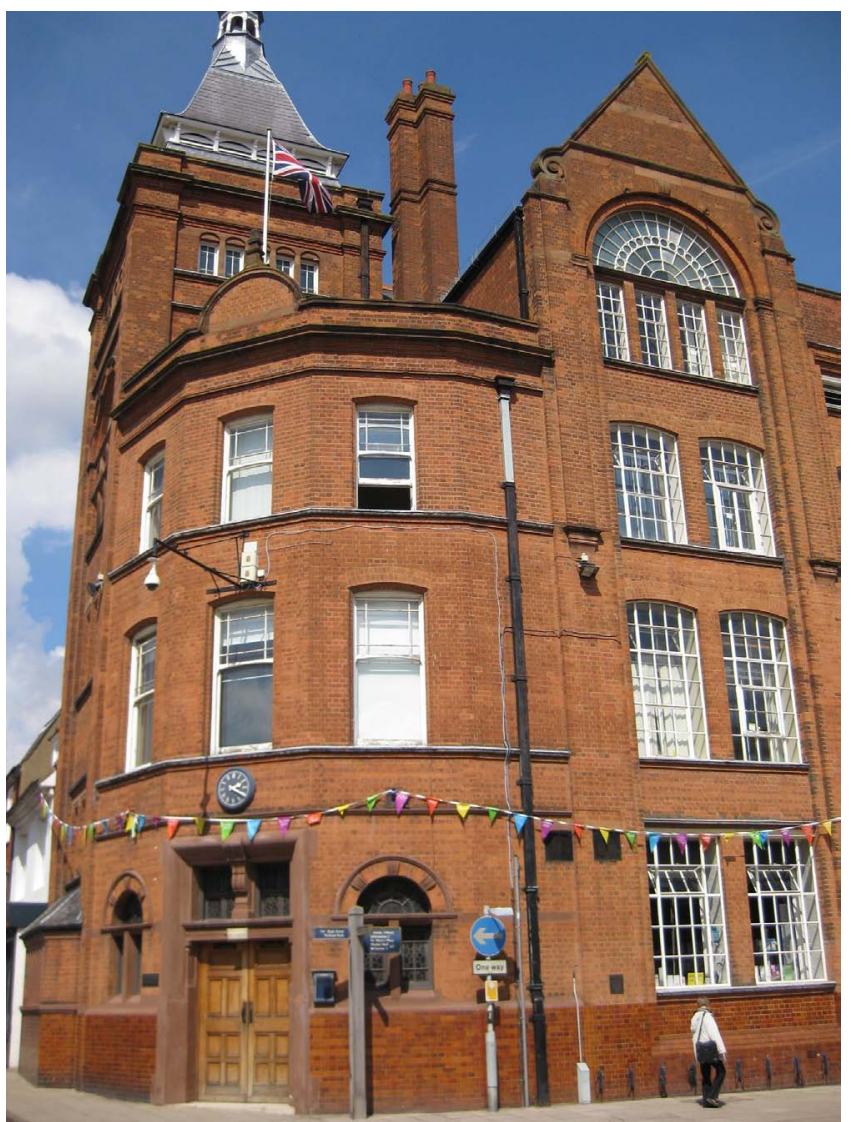

Figure 7. The Symington Building, Market Harborough 


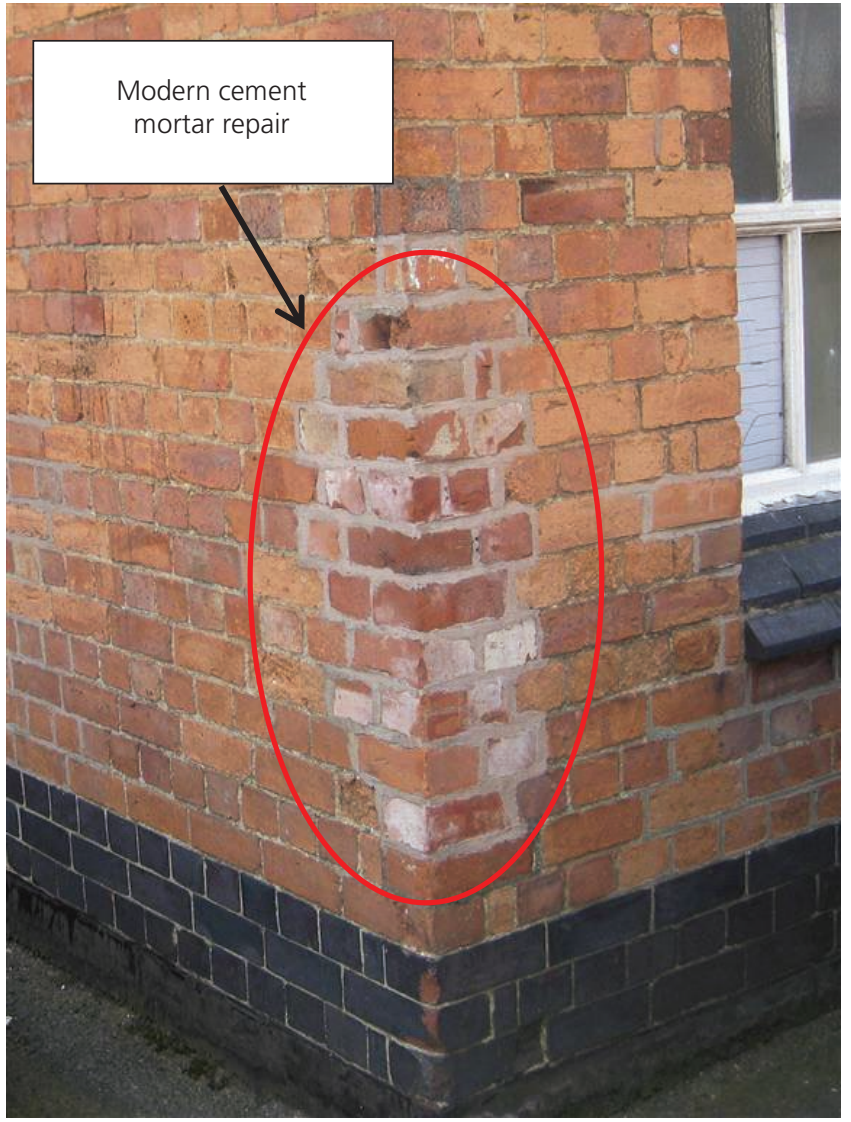

Figure 8. Evidence of modern cement mortar repairs around the perimeter of the Symington Building

therefore, much of the original fabric was retained. In this case, although the perimeter brickwork appeared to have been damaged from decay, rather than replacing these imperfect materials entirely, the walls have been preserved as found. The intervention was the removal and replacement of previous repairs that were detrimental to the performance of the original fabric. This is a simple example illustrating that historic buildings will function well if they are allowed to work as they were originally intended to.

\subsection{Illustrating minimum intervention at St Pancras Renaissance Hotel, London}

At St Pancras Renaissance Hotel, the roof structures generally consisted of timber roof trusses. The approach adopted and agreed with English Heritage (as it then was) and building control was to strike a balance between the cost of investigation works and the level of confidence that an acceptably accurate picture of the building's characteristics had been obtained.

Much of the roof structure was considered to be unaffected by new intervention works in the building; therefore, the question here was, to what extent is it necessary to investigate the strength, condition and any previous repair works to these elements? Given that the building was over a hundred years old, where the timber did not show any signs of distress, there was no anticipated change in loading and the structural load paths remained unaltered, then it should continue to perform as it currently does. The timber members were all surveyed to identify any signs of decay and deterioration with only localised repairs and avoiding replacing large areas of the original members (Lazarus and Lange, 2009).

However, it was not possible to adopt this minimal intervention approach throughout the building. The existing building had been unoccupied for a period, and while no significant structural deterioration that could affect its continued performance was identified for the majority of areas, some parts had suffered some more serious degradation. In these cases, interventions were considered necessary. New slabs have been inserted to support the heavier loading required for plant, kitchen and cold storage areas. In addition, new staircase and lift cores have been introduced to improve circulation and satisfy the fire strategy requirements. These insertions have required a more contemporary structural design, but the design principles adopted were to follow clear and simple engineering guidelines by maintaining the existing load paths and avoid localised loading of unproved elements to ensure global balance of loading.

\section{Like-for-like materials}

Sometimes it is not possible to take the approach to preserve as found, with problems identified requiring urgent attention and needing to be rectified. Where interventions are required, they should be carefully considered and sympathetic to the character of the building. Often the use of like-for-like materials and construction techniques used at that time are appropriate interventions.

When using like-for-like materials, it is important to understand the materials used and construction techniques adopted at the time. This will help to develop an appreciation of the behaviour of the original structural systems and of the existing fabric. The use of like-for-like materials for any repair works is an honest intervention. The general approach should be to carry out a genuine intervention which is true to its generation, rather than a pastiche or a 'pretend' version of something old.

This approach can be made to be representative of a specific period or style, which can help to maintain the historical value and not detract from the nature of the building. However, while it is important that any interventions are respectful and integrate harmoniously with the whole, they must also be distinguishable from the original construction.

\subsection{Illustrating like-for-like materials at Wentworth Castle Gardens}

Various investigations and surveys were carried out on the different estate buildings and outhouses across the Grade I-listed Wentworth Castle Gardens as part of the restoration and conversion works across the site. These inspections identified numerous defects, many of which were the result of a lack of 
Engineering History and Heritage

Volume 170 Issue EH2
Engineer's approach to conservation

Fernandez maintenance, general wear and deterioration of the fabric. This was not considered unusual for buildings of this type and age, but other defects observed had resulted from large movements and were more concerning (see Figure 9). The scale of these movements was such that usual causes of localised building movement and settlement were not considered to apply (such as shrinkable clays beneath foundations, trees in close proximity, leaking drains and local structural instability).

Given the scale of defects and movements, the buildings, structures and ground levels were monitored to understand if there was any ongoing movement, but it was not considered appropriate to leap into repair works (although repairs were prioritised where there was concern over structural integrity and stability).

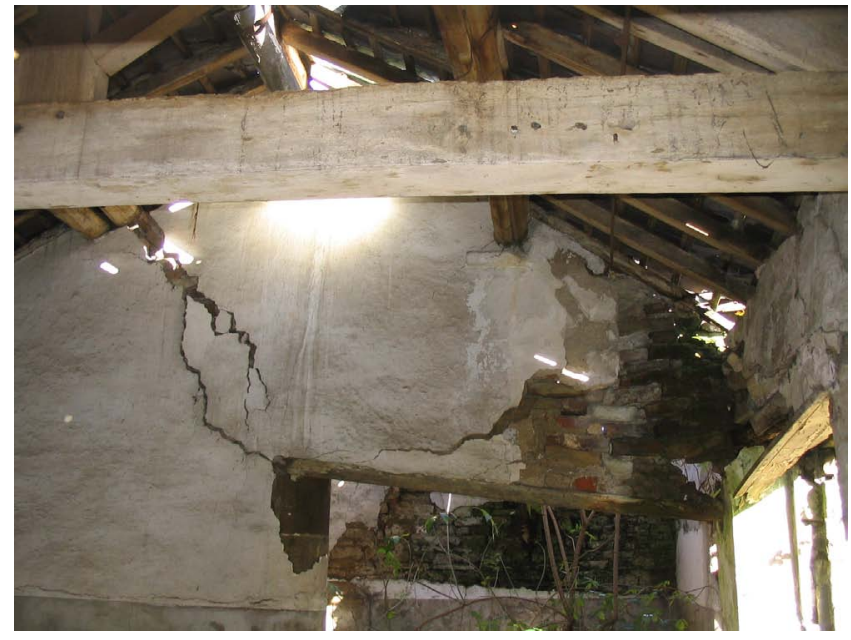

Figure 9. Evidence of settlement on numerous buildings on the Wentworth Castle Garden estate

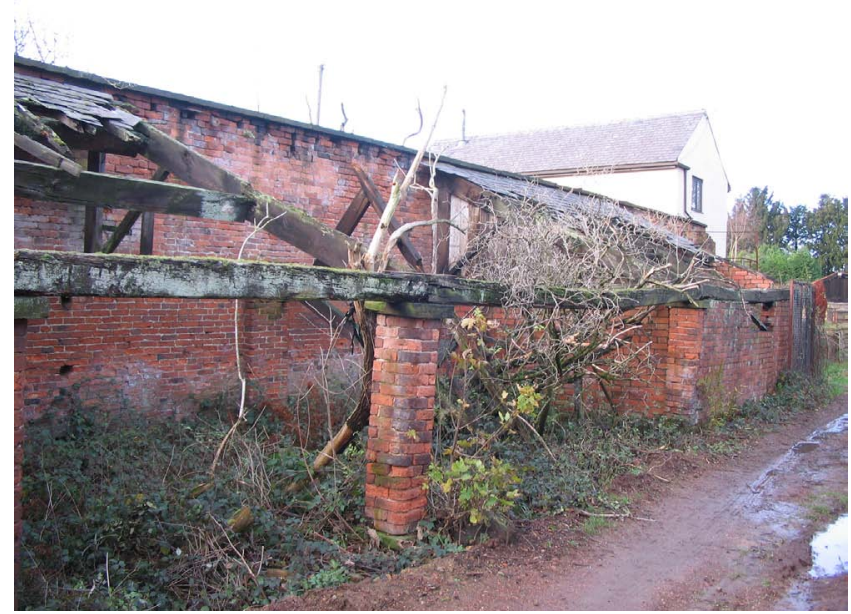

Figure 10. Existing structures on the Wentworth Castle Garden estate
The buildings varied across the grounds, but generally consisted of load-bearing masonry with timber floor joists (where upper floors occur) and timber roof structures. Detailed inspections were carried out where structures were still present, and the condition of the timber also varied and, in some cases, it was no longer present (see Figure 10). Generally, the existing timber appeared to be in good condition, but some areas had suffered beetle attack, other parts had suffered wet rot and some elements showed signs of splitting at connections and where previous remedial support had been introduced (see Figure 11).

Where possible, repair works involved introducing new bolts or screws to connect timber elements that had split. Where existing joints were considered to be inadequate, only the defective timber was cut out, ensuring that as much of the existing was retained, and new timber was spliced onto the existing one by using a traditional carpentry repair. In this way as much as possible of the original fabric was retained and can be classified as a 'traditional' repair, which maintains the original appearance, but is an 'honest' and obvious repair which does not detract from the nature of the building (see Figure 12).

Roofs and ceilings that had decayed or were no longer present were reinstated using similar construction techniques and materials as the original, and in this way the interventions have brought the buildings back to their original state without using modern materials.

\subsection{Illustrating like-for-like materials at the Arkwright Building, Nottingham}

In the Arkwright Building, the Technical School was one area where very little structural modification was anticipated and assumed to be in relatively good condition without any immediate signs of distress. The two-storey structure consists of steeply

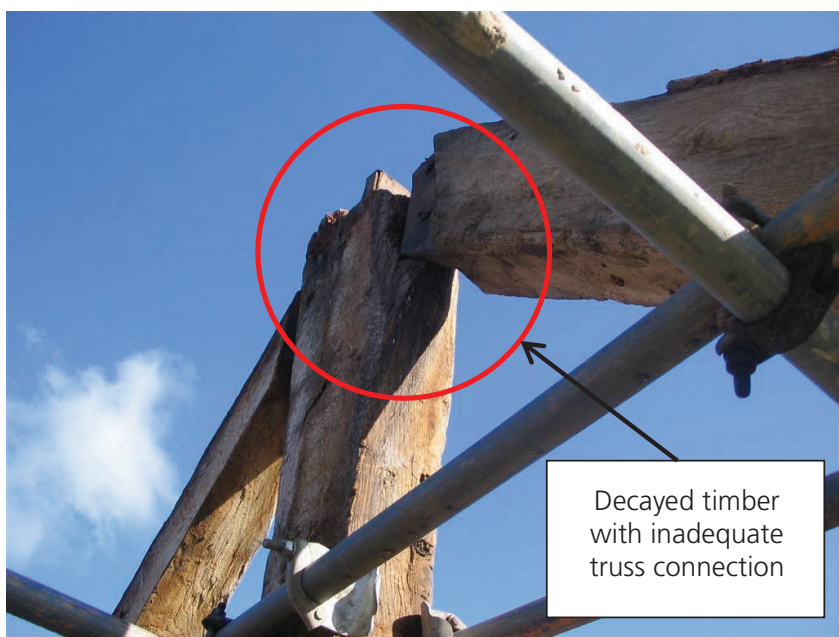

Figure 11. Parts of the existing timber roof trusses were found to be decayed and the structural integrity was considered to have been compromised 
Engineer's approach to conservation Fernandez

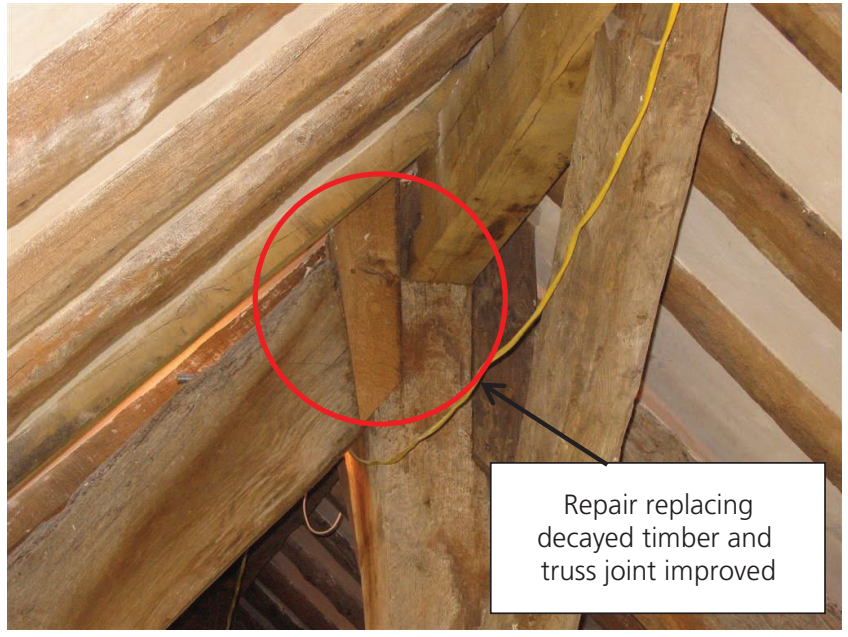

Figure 12. Honest timber repairs for the existing roof structure in one of the buildings at Wentworth Castle

pitched timber trusses supporting timber purlins and rafters spanning onto the perimeter load-bearing masonry.

The timber purlins, rafters and trusses were found to be in good condition, including the connections. However, as the timber trusses were built into the perimeter solid masonry walls, local opening-up revealed that some of the timber had decayed (see Figures 13 and 14). As the roof profile is relatively steep, adequate falls appeared to have been provided to ensure that rainwater could run off the roof. There were no signs of significant deflection or sagging of the purlins or rafters (which, if present, might have resulted in rainwater collecting and ponding). The loft space was relatively large and appeared to have been ventilated sufficiently, so any moisture in the area would have

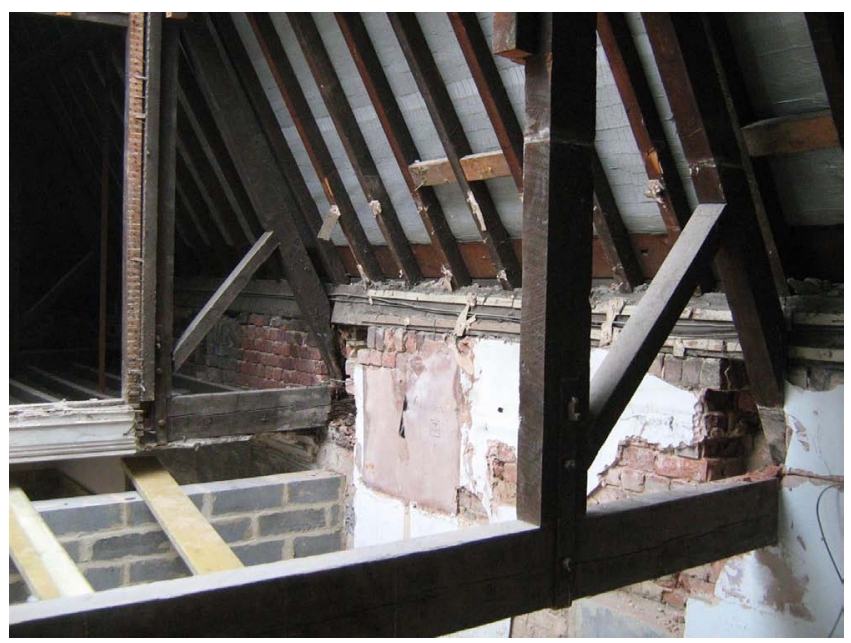

Figure 13. Local opening-up works to fully inspect the extent of decay in the Arkwright Technical School been able to escape. Also, there were no signs of modifications which might have reduced the ventilation of the space. The inspections established that the ingress of water was a consequence of the gutters being poorly maintained and blocked due to being filled with debris, with rainwater overspilling the gutters and saturating the masonry wall.

The decayed timber was confirmed as wet rot, which tends to grow on porous surfaces where the timber can have a high moisture content. All types of fungal attack in timber require water, air and food (the timber); therefore, the ingress of water through the wall had provided the perfect environment for the decay of the timber embedded in the wall.

In these situations, the types of questions that should be asked are the following: Were there any shortcomings in the original design? Were there any historical modifications that might have caused the decay? Was the decay the result of a lack of maintenance? Do the same details and defects occur elsewhere and therefore could be more widespread?

The repair detail agreed with English Heritage for the decayed timber truss was to use like-for-like materials. This involved cutting out the decayed timber and connecting new timber, spliced onto the existing one by using a bolted scarf joint, to provide a direct replacement for the decayed part (see Figure 15). The gutters were cleaned and surveyed to ensure that rainwater was adequately collected and drained. This approach ensured that the previous cause of the decay had been removed, and the importance of adequate maintenance was highlighted to the client to minimise the risk for future defects.

However, the majority of timber trusses were not repaired. Although they were found to be saturated, there was no

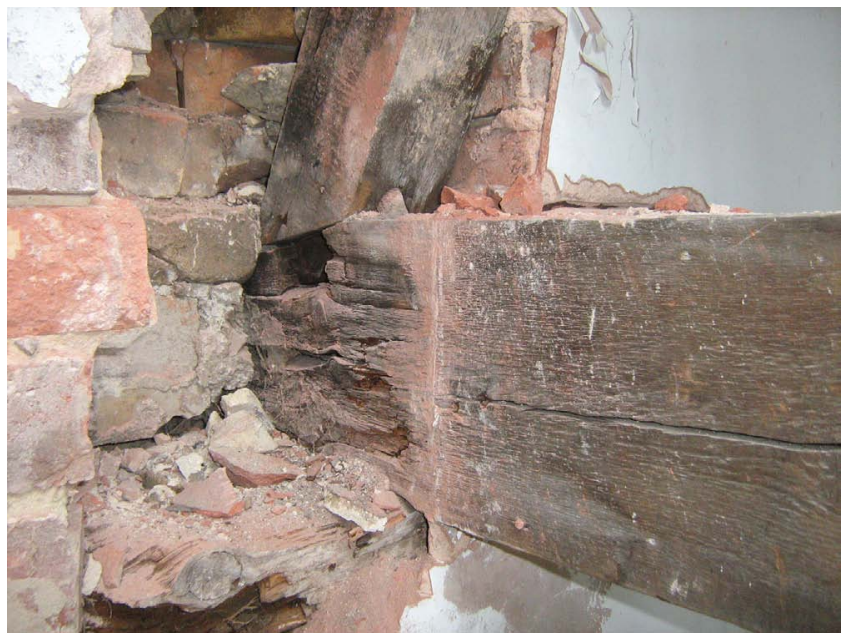

Figure 14. Extent of truss decay where the timber was embedded into the existing wall in the Technical School in the Arkwright Building 

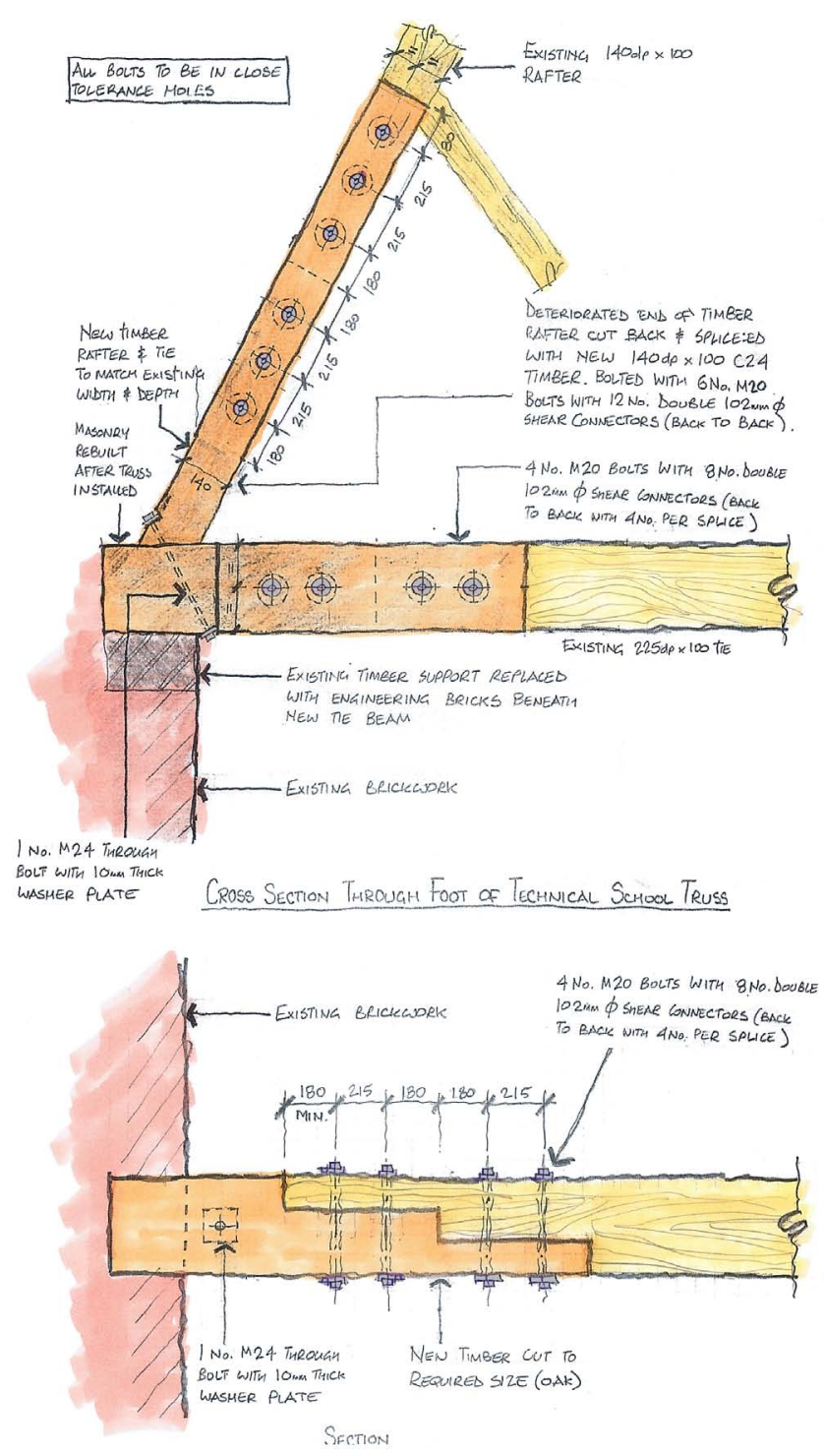

Figure 15. Following detailed assessments of the decayed timber, the repair detail developed involved splicing new timber onto the existing one by using a traditional carpentry repair

significant loss of section from decay, and addressing the problem at the source helped to retain much of the original fabric. In addition to the repair works, the area was monitored for several months to ensure that historical water ingress had been rectified. This example is a reminder of the serious damage that can result from failure to keep water out of a building: even a minor amount of ingress, if left untreated, can result in disproportionate and costly damage.

It was considered necessary to carry out a structural intervention to preserve the life and ensure the longevity of these elements, but it was possible to limit the extent of repair works and conserve as much of the original fabric as possible. The repair is an obvious one, but is respectful of the original materials and form of construction.

\section{Reversible interventions}

There are limitations to using like-for-like materials, as traditional repair methods can have limited structural performance and often require skilled craftsmen, who are in short supply today. The use of like-for-like materials can often result in some of the original fabric being lost. Also, although any changes should be well recorded (BS 7913:2013 recommends that records should be kept for any changes), this has not always been the case. Where like-for-like materials have been used and this is not documented, the works can give misleading information on the age of the structure to future generations.

When intervention is necessary, alterations to the original fabric should be limited and as far as possible be reversible without damage. This ensures that any intervention can be removed in the future during another phase in its life, leaving minimal indication of the intervention.

The use of like-for-like materials is obviously the preferred approach as it can result in an inconspicuous repair, but sometimes modern materials and techniques can actually save more of the building in the longer term. The purpose of conservation work is to preserve the original building or monument for the future, and given that some materials and details may result in premature deterioration or decay, it may be more appropriate to use modern approaches. However, any intervention must be carefully considered on its own merits.

Where interventions are introduced, these should be unobtrusive and as sympathetic as possible. It is worth noting that the most straightforward structural repair or intervention to solve a problem may not be the most aesthetic and appropriate one. Interventions should not only be discreet and respectful of the character of the original building, but also be honest without trying to disguise the fact that it exists. The approach towards interventions should be minimised and designed wherever possible to be reversible, which will allow the intervention to be removed in the future without damaging the original fabric. However, this may not always be possible or even appropriate. This therefore requires careful judgement, and carrying out any intervention is an art in itself. While it may be relatively straightforward to design repairs by using current codes of practice, they do need careful consideration as the result may be visually unattractive. Even if more modern materials are used, the repair should be honest to ensure that the modifications are obvious, and importantly every effort should be made to ensure that they are fully reversible.

\subsection{Illustrating reversible interventions at the Burngreave Vestry Hall, Sheffield}

The Grade II-listed Burngreave Vestry Hall in Sheffield had unfortunately been closed for several years due to settlement problems, occupied only by squatters and drug users and was consequentially in a poor condition (see Figure 16). Numerous leaks had allowed water to enter the building, and the majority of timber floor joists were severely decayed. The rotten timbers were so extensive that repairs were not considered practical; therefore, the timbers needed to be replaced entirely (see Figure 17). 


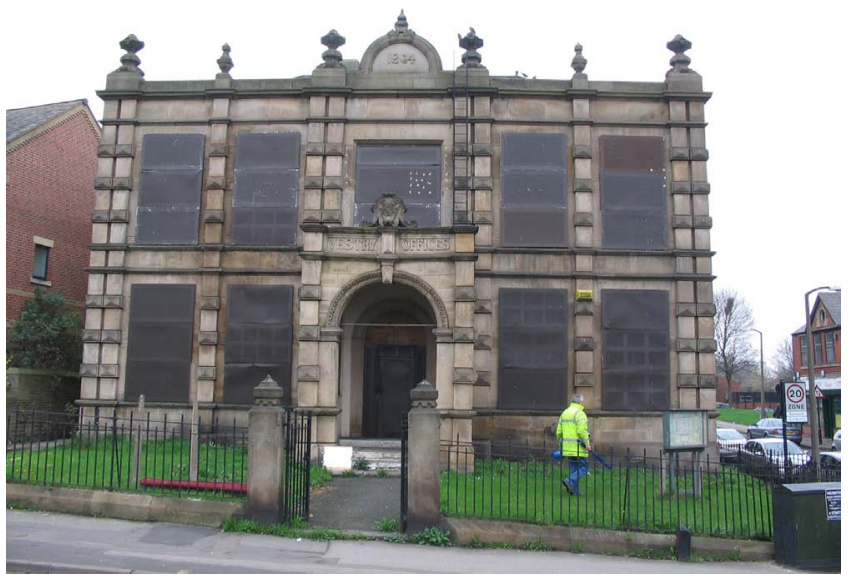

Figure 16. The Vestry Hall building was unused and boarded up and had suffered from water ingress for several years

New floors have been introduced into the building, supported on the existing load-bearing walls but with improved connections to the walls. As expected for this type of construction, the timber joists were embedded in the solid masonry walls. As the floors were replaced entirely, the bearing detail was modified with new timberbearing plates installed on the internal face rather than embedding the timber into the existing pockets in the walls. Also, the floors were strapped to the walls as the previous floor had not provided sufficient restraint, which had resulted in some bowing and cracking.

It can be argued that the approach here is not reversible due to the removal of a significant amount of the original fabric. However, given the poor condition of the existing fabric, this intervention was considered essential in order to bring the building back into use while retaining as much of the original building as practical.

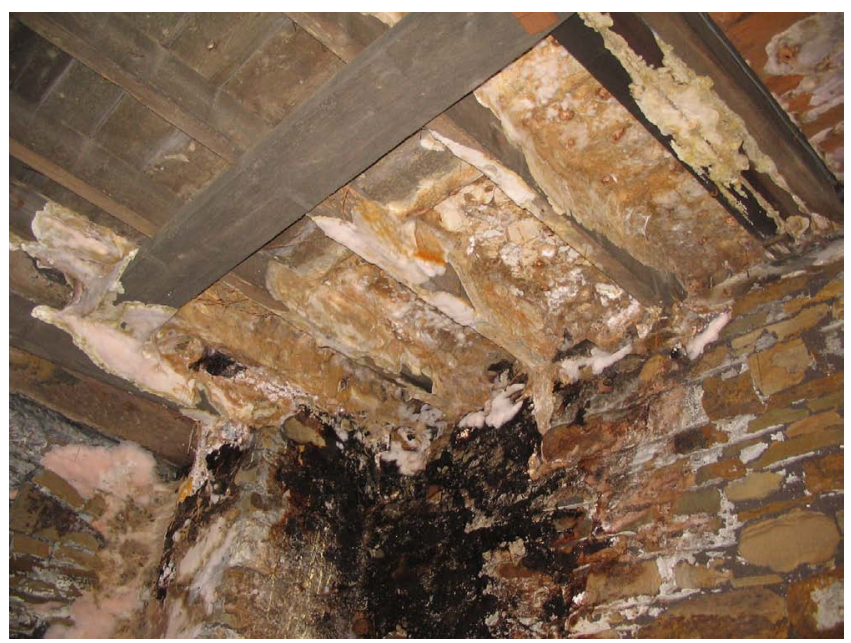

Figure 17. Severely rotten timber floor joists were identified as part of the detailed surveys at Vestry Hall and their reuse was not practical

\subsection{Illustrating reversible interventions at Wentworth Castle Gardens}

The estate buildings at Wentworth Castle Gardens generally consist of load-bearing masonry walls with timber trusses supporting timber purlins and rafters, or timber purlins and rafters for the smaller structures. The ends of the primary timber trusses were found to be embedded into the solid masonry perimeter walls and, at these locations, some members were found to be severely decayed. Rather than attempting a splice detail for these trusses, the repair works consisted of bolting pairs of new steel channels and plates onto the existing timber members, which is a modern repair but retains much of the original fabric (see Figure 18).

The load path from the existing truss has been altered locally by transferring the forces from the truss into the new arrangement of steelwork and back into the load-bearing wall. However, these modifications to the existing structure are obviously a modern intervention and the bolted arrangement of steelwork ensures that the repair is entirely reversible.

\subsection{Illustrating reversible interventions at the Arkwright Building, Nottingham}

The existing spire over the main entrance in the Arkwright Building was found to be supported by a timber structural system consisting of a 'pyramid' arrangement of raking timber members bearing onto the load-bearing masonry walls. As some structural modification works were proposed in this area and given the building's historic settlement problems, further investigation was required to ensure that the structural integrity would not be compromised.

The structure supporting the spire appeared to apply a lateral thrust on the wall. To prevent any further thrust, the base of the timber members have been tied together with a new 'ring beam'. This has been introduced within the ceiling void by using a combination of small steel channels and tie rods clamped onto the
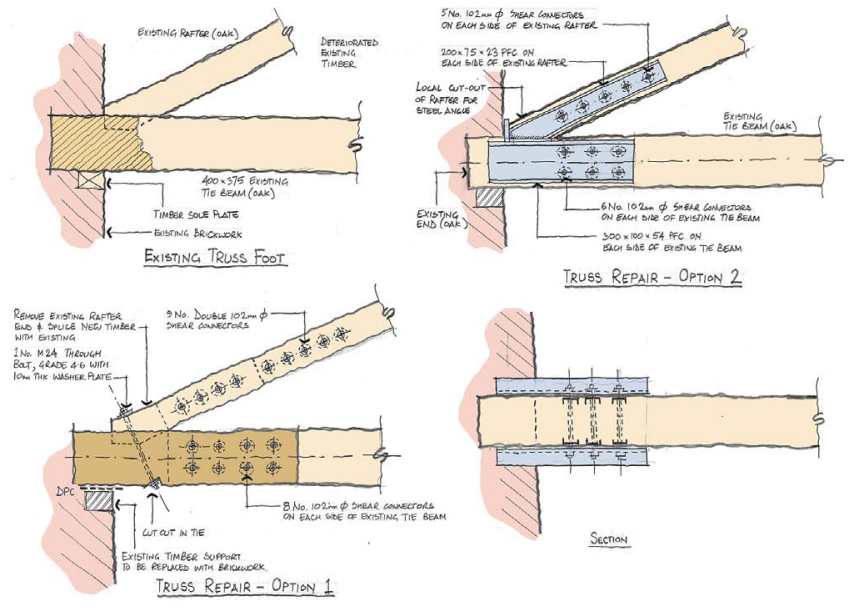

Figure 18. Different options considered for the repair to improve the existing timber truss bearing detail 
existing timbers (see Figure 19). This intervention is entirely removable and could be easily replaced at a later date.

\section{Change of use}

A change of use for a building can sometimes be extremely beneficial as it can give it a new lease of life, and ensuring that it is occupied will help to ensure that it is maintained. It is often a positive step if existing unoccupied buildings are given a new use for a socially useful purpose, but it must not fundamentally change the layout or decoration of the building. Therefore, caution must be taken when carrying out major alteration works, particularly if they could have an adverse effect on the historical integrity. For example, converting historic buildings to incorporate shops at the ground level with limited supports or open-plan offices may require a radical transformation of the original structural form and is likely to require removing a substantial amount of the historic fabric. Each building has many layers, and the elements that make up the building are all important parts of its journey through history. Even if it has been adapted and changed over the years, these alterations are all part of its history. However, it is important to recognise that some modifications might have been ill considered and might have adversely affected the building. In these cases, it is not clear what the best approach should be. Perhaps these modifications would be better removed or altered, or alternatively should further change be avoided? Whichever course of action is taken, it must be carefully considered.

One obvious challenge to change of use is justifying floor loadings in historic buildings to current codes of practice, as many will rarely conform. Many historic buildings did not actually have any structural design, and elements were installed based on experience. Therefore, justifying floors and elements to support loading to current codes of practice can be difficult. In the past, irreversible and unnecessary loss of fabric has been caused by taking a blanket approach to institutional floor loading and concluding that significant strengthening works are necessary (Hume and Miller, 2015).

The guidance in a document produced by English Heritage (1994), Office Floor Loading in Historic Buildings, describes the problems associated with accommodating office floor loadings in older buildings, which suggests that actual loads applied to floors are usually significantly lower than loadings imposed on designers by current codes of practice. It suggests that the common use of a blanket imposed floor loading of $5.0 \mathrm{kN} / \mathrm{m}^{2}$ for offices can be overly conservative and that $2.5 \mathrm{kN} / \mathrm{m}^{2}$ is often more than adequate for this use. This guidance is specifically for office floor loading, but it highlights that perhaps a similar philosophy should be considered when assessing loads on historic floors, particularly if there is to be a change of use.

Taking the approach that a historic building needs to be capable of supporting higher loads than necessary can all too easily result in major structural interventions. The 'perceived' requirement for high floor loadings can have cost implications and may also result in significant loss of historic fabric. A more practical approach could be to develop a better understanding of the original design loads and to ensure that the new use respects these. This approach may require limiting occupancy levels or specific uses for particular areas. When considering loadings, it is important to assess realistic loadings without compromising the flexibility or structural safety. It is worth asking the following: Are higher floor loadings (to give flexibility of use) really justified? Or can a lower value be used without compromising the flexibility or structural

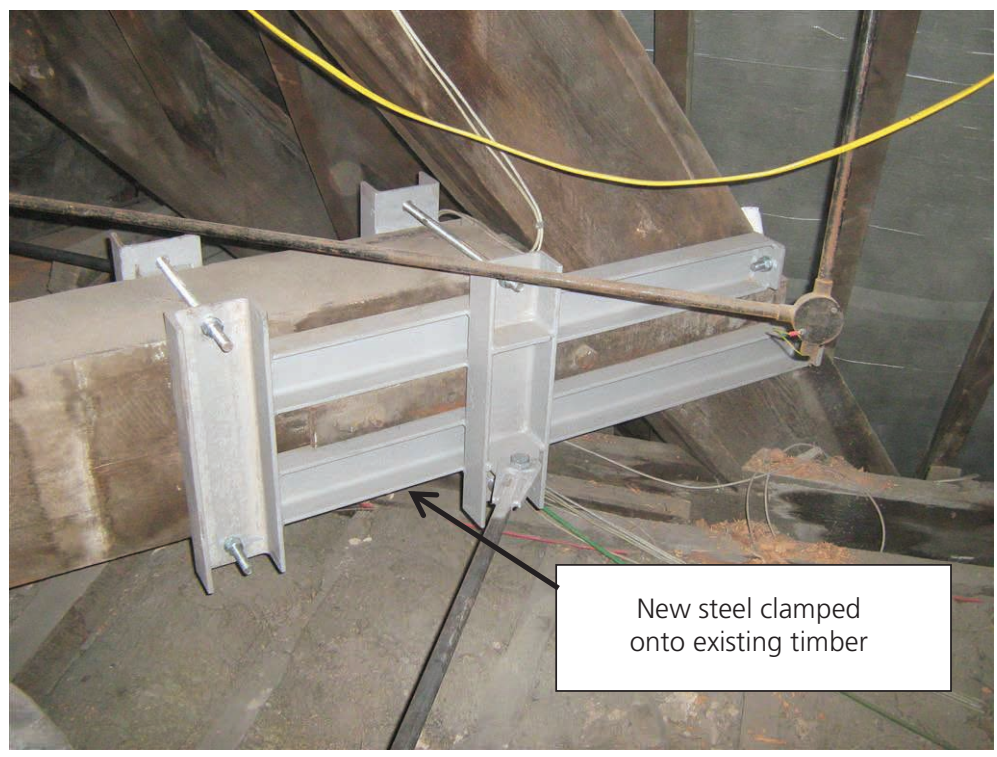

Figure 19. Reversible interventions in the Arkwright Building with new steel restraints and ties clamped onto existing timbers to prevent outward thrust of the structure supporting the spire 
safety? It is important that the use of the building be not overly restricted by the loading that the floors are capable of carrying, but equally, it may not be necessary to upgrade floors to make them capable of carrying loads which will never be imposed.

\subsection{Illustrating change of use at the Newton Building, Nottingham}

The Newton Building at Nottingham Trent University is a 1950s' Grade II*-listed building. It is a nine-storey tower over a twostorey podium, faced with Portland stone (see Figure 20). The basic structural design philosophy was to minimise the alterations to the existing structure and to limit the repair and enhancement to the essential minimum.

The building was originally designed to be used for lecture rooms, academic offices and laboratory spaces, and over the years, the structure proved to be adequate for carrying the loading associated with these uses. The proposal was to strip the building internally back to the structural frame, removing all existing services, suspended ceilings and internal non-load-bearing walls. Prior to carrying out any works, it was valuable to carry out a detailed appraisal and assessment of all the loads applied to the building.

It was considered more important to understand thoroughly the building and its structure than assessing whether the members comply with current code requirements for stress and deflection, or jumping to the conclusion that strengthening works need to be carried out. The information gathered through the surveys was used to compare the existing superimposed dead loads and likely applied live loads with the proposed loadings and an overall 'load

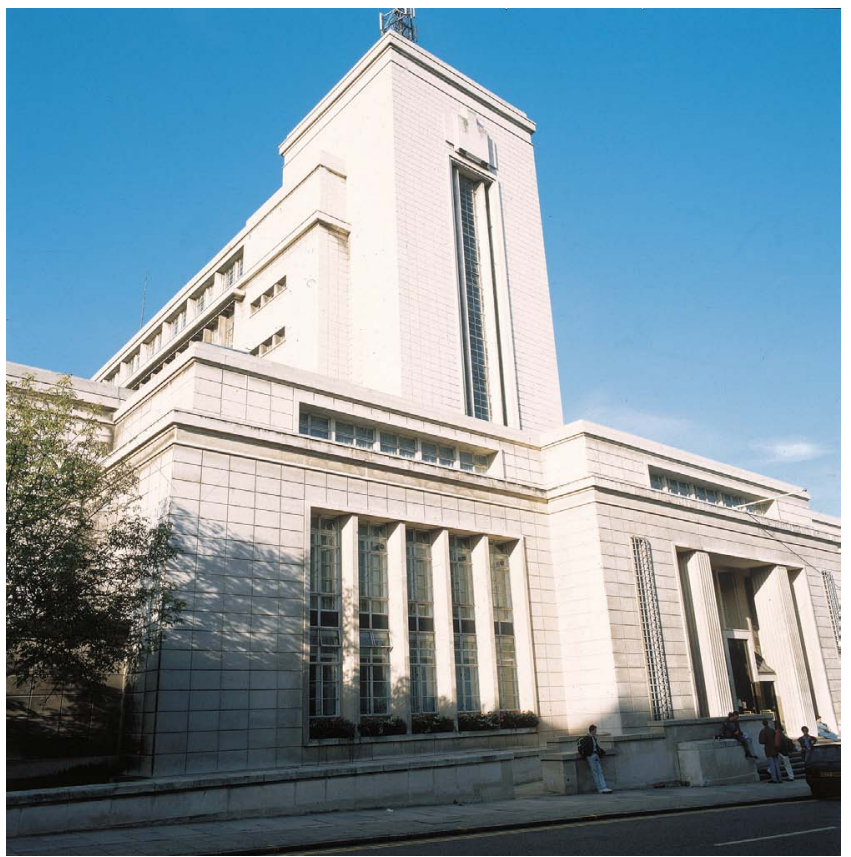

Figure 20. The Newton Building, Nottingham balance' approach was taken. New required floor loads in the building were matched to the existing uses in order to justify that there would be no significant change of use (see Figure 21). This approach was discussed and agreed with building control and avoided the need to carry out extensive 'back-justification' calculations to try and establish the theoretical design floor capacities. In this case, this would be particularly onerous as so little design information was available and, given the relatively good condition of the existing structure, avoided the need for costly structural enhancements to the typical floor plates.

\subsection{Illustrating change of use at the Symington Building, Market Harborough}

It may also be appropriate to research historical uses, what loads a building has carried and what modifications have been carried out (archive searches may need to be thorough to validate loading assumptions).

The library located in the Symington Building held existing drawings, historical photographs and various articles describing the use of the building. This information described the form of the building and extensions that had been added but, more importantly, the photographs illustrated the uses on the various floors. The use of the building had changed from its original use as a factory (see Figure 22). The photographs showed that the floors were subjected to large loadings when used as a factory; therefore, the loading to current codes of practice for its new use as offices, library, retail areas and museum was considered acceptable. Various inspections indicated that the existing structure was in relatively good condition with no obvious signs of distress; therefore, it was considered acceptable to carry the new loading without any strengthening works and minimise the level of intervention.

Historic buildings that have lasted generally function quite well, and if a change of use is proposed, this does not necessarily have to mean a significant change in loading. Rather than jumping to the conclusion that it needs to be designed to current codes of practice, it is more important to have early discussions with the client and architect to consider carefully realistic loading in order to minimise any strengthening to only what is essential. It is possible to justify avoiding the adoption of unrealistic high design loads with some early considerations and following simple guidelines on anticipated activities.

\section{The role of the conservation engineer}

Structural engineers working on conservation projects will not only often face similar challenges encountered by any engineer, but also be exposed to numerous additional challenges. It is essential to be conversant with the philosophy of conservation and have an appreciation of wider interests and disciplines. The role not only is associated with carrying out repair works or adding new elements to existing buildings or assets, but critically is also about understanding the historic fabric, cultural or artistic values and transferring these values to current and future generations (Theodossopoulos, 2012). 


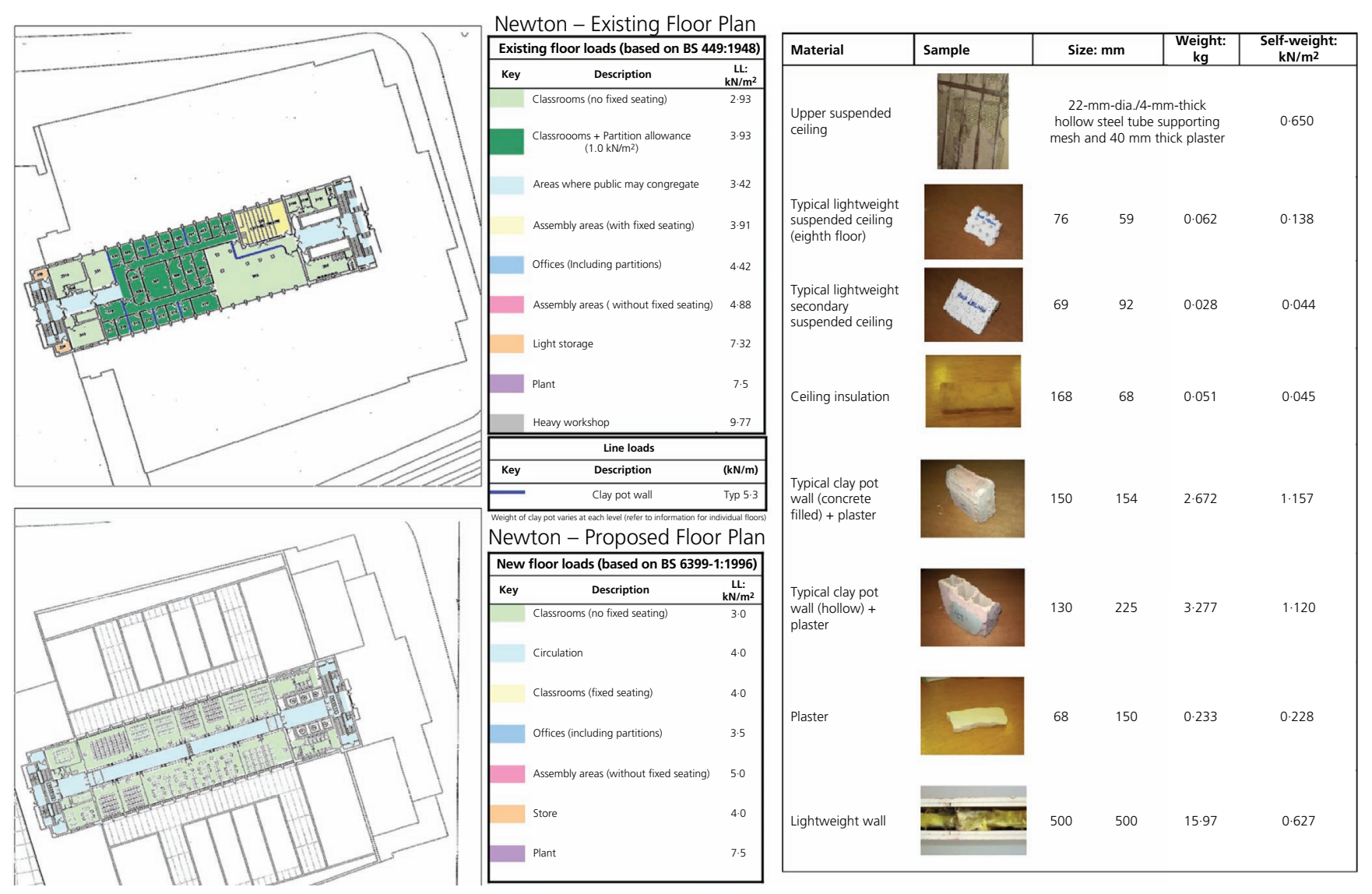

Figure 21. Determining weights of existing finishes and comparing original loading with proposed loading at the Newton Building

Built heritage has developed and evolved over the years, with different materials and techniques discovered and used in different periods of history. The conservation engineer must appreciate this history and understand the range of materials and methods that were used at different times. It is essential to understand the

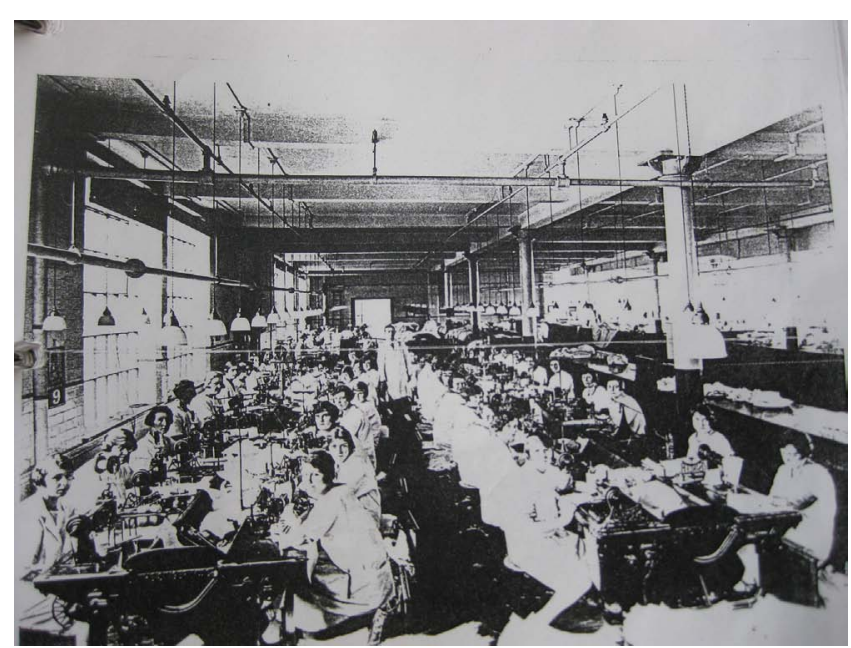

Figure 22. Review of historical information at the Symington Building to identify historical floor loading and determine loads the structure may have been designed for (rather than back-justifying) behaviour of a wide range of materials, existing fabric and construction techniques and also have practical experience which can applied to historic projects (Avent, 2010).

As well as developing a technical understanding of the building or asset, the conservation engineer must also appreciate any important characteristics and historical significance of the fabric. This means that the role becomes increasingly more complex and requires consideration of a wider range of parameters and influences. Therefore, it is necessary for the conservation engineer to bring a combination of technical and cultural expertise to any conservation works, and this will help preserve the life of cultural heritage.

The role of the conservation engineer does not simply involve protecting heritage assets. Conservation works may require integrating 'new' with 'old', and it may be necessary to develop reasoned arguments to justify the works. This may involve developing a conservation strategy and determining the appropriate level of intervention where necessary.

There may not be a detailed prescriptive approach, but it is important to understand theories, regulations and charters which will all help the conservation engineer to exercise an educated judgement towards whether an intervention is necessary, the level of intervention or modification and how it can be integrated without damaging the 
character of the building or asset. A key challenge often encountered is addressing the conflicting objectives between commercial pressures and the approach towards conservation. The conservation engineer needs to be able to balance needs and expectations with the requirement to intervene and any disruption of the original fabric requires careful consideration.

\section{Conclusion}

When carrying out any conservation work, it is important to develop first a better understanding of the building or asset. This can be gained from a variety of available sources of information, to appreciate the original design, rationale, materials and construction, and can help to inform design decisions for any modifications or remedial works that may be required.

Engineers need to consider wider aspects, such as appreciating the architectural language and understanding the important aesthetic qualities, to ensure that any works carried out will preserve the original design intent and any interventions will act complementarily. Any type of intervention or alteration, even a small repair, could change the appearance or character and will have an impact on the original aesthetic qualities; therefore, it is essential to have this awareness and exercise aesthetic judgment when designing any modification works.

Another important part of conservation is identifying defects that may be present and developing an understanding of the cause. This may involve carrying out surveys, which initially may involve carrying out non-intrusive visual inspections, followed by detailed surveys, and it may also be necessary to seek specialist input. This helps to build a fuller picture and develop a better understanding of the existing structure and its construction, identify any potential issues to determine its condition, diagnose any causes of decay and inform what action needs to be taken. Any intrusive and invasive opening-up works should also be minimised to ensure that as much of the original fabric is retained as possible and should be carried out only after the non-intrusive visual inspections have been completed (as, in some cases, opening-up works can be avoided).

In order to address any potential remedial works, there may be a number of different solutions, each with its own implications. A flexible approach is required and balanced judgements need to be made, considering the long-term welfare of the cultural heritage and also technical, functional and cost constraints. Consideration should be given to the reversibility of any intervention and retaining as much of the original fabric as possible. This may not always be practical and therefore needs to be evaluated specifically on a caseby-case basis. Conservation is not just about the built form, but also requires good decision-making. This needs to consider cultural, economic and environmental objectives, and the approach adopted should be an appropriate balance between these.

For the engineer, it is important to appreciate the philosophy of conservation and develop the necessary judgement as to how this can be best applied on a given project. Any works must be carried out sympathetically, and while minimal intervention should be the starting point, some change may be inevitable. The best chance of survival for any historic building or asset is for it to have a practical and economic use, and this requires the engineer to be capable of determining the most appropriate approach.

\section{REFERENCES}

Avent J (2010) Raising the profile of conservation. The Structural Engineer 88(11): 13-15.

BSI (2013) BS 7913:2013: Guide to the principles of the conservation of historic buildings. BSI, London, UK.

Department for Communities Local Government (2012) National Planning Policy Framework. Department for Communities and Local Government, London, UK.

English Heritage (1994) Office Floor Loading in Historic Buildings. English Heritage, London, UK

English Heritage (2008) Conservation Principles, Policies and Guidance for the Sustainable Management of the Historic Environment. English Heritage, London, UK

Hallum AJ (2006) Our role in conservation. The Structural Engineer 84(6): 29-38.

Hughes P (1986) The Need for Old Buildings to 'Breathe'. Society for the Protection of Ancient Buildings, London, UK, Information Sheet 4.

Hume IJ (1997) The structural engineer in conservation. The Structural Engineer 75(3): 33-37.

Hume I and Miller J (2015) Conservation compendium - part 7: imposed load in historic buildings: assessing what is real. The Structural Engineer 93(6): 40-43.

Icomos (International Council on Monuments and Sites) (1931) 1st International Congress of Architects and Technicians of Historic Monuments. The Athens Charter for the Restoration of Historic Monuments. Icomos, Paris, France. See www.icomos.org/en/chartersand-texts/179-articles-en-francais/ressources/charters-and-standards/ 167-the-athens-charter-for-the-restoration-of-historic-monuments (accessed 29/12/2016).

Icomos (1964) 2nd International Congress of Architects and Technicians of Historic Monuments. The Venice Charter for the Conservation and Restoration of Monuments and Sites. Icomos, Paris, France. See www. international.icomos.org/charters/venice_e.pdf (accessed 29/12/2016).

Lazarus D and Lange J (2009) St Pancras Renaissance Hotel, London - a future for the past. Engineering History and Heritage 162(4): 189-197, http://dx.doi.org/10.1680/ehah.2009.162.4.189.

Prizeman O (2015) Sustainable Building Conservation. Riba Publishing, London, UK.

Theodossopoulos D (2012) Structural Design in Building Conservation. Routledge, Oxford, UK

\section{How can you contribute?}

To discuss this paper, please email up to 500 words to the editor at journals@ice.org.uk. Your contribution will be forwarded to the author(s) for a reply and, if considered appropriate by the editorial board, it will be published as discussion in a future issue of the journal.

Proceedings journals rely entirely on contributions from the civil engineering profession (and allied disciplines). Information about how to submit your paper online is available at www.icevirtuallibrary.com/page/authors, where you will also find detailed author guidelines. 